\title{
Late-onset superior mesenteric artery syndrome four years following scoliosis surgery - a case report
}

\author{
Nariman Abol Oyoun ${ }^{1,2}$, Muayad Kadhim², and John P. Dormans ${ }^{2, *}$ \\ 1 Department of Orthopaedic Surgery, Assiut University Hospital, Assiut 71526, Egypt \\ 2 Division of Orthopaedic Surgery, The Children's Hospital of Philadelphia, 3401 Civic Center Boulevard, Philadelphia PA 19104, USA
}

Received 26 March 2015, Accepted 29 April 2015, Published online 15 June 2015

\begin{abstract}
Background: Superior mesenteric artery (SMA) syndrome has been reported as an uncommon condition of external vascular compression of the SMA particularly after rapid weight loss, body casts, or after corrective surgery for spinal deformities, usually within the first few weeks after surgery.

Methods: This is a retrospective report of a case of a non-verbal autistic female patient who started to develop SMA syndrome at the age of 16, 4 years after posterior spinal fusion surgery for scoliosis. She was treated conservatively by increasing oral caloric intake, which resulted in increased body weight and relief of symptoms.

Results: Seen at 10 years' follow up, the patient is doing well, and is functional within the limits of her suboptimal cognitive and verbal conditions. She maintains good trunk balance with solid spinal fusion and intact instrumentation at latest follow up.

Conclusion: Spinal surgeons should maintain a high index of suspicion for diagnosis of SMA syndrome even years after scoliosis surgery, especially for patients with communication problems, like the case we present here. Appropriate conservative measures can succeed in relieving the symptoms, increasing body weight, and preventing complications including the risk of death.
\end{abstract}

Key words: Superior Mesenteric Artery, SMA Syndrome, Scoliosis, Spinal fusion.

\section{Introduction}

Superior mesenteric artery syndrome (SMAS) is an uncommon condition of the gastrointestinal (GI) tract with external vascular compression of the third part of the duodenum causing partial or complete obstruction secondary to decreased aortomesenteric angle and distance to $6-16^{\circ}$ and 2-8 mm, respectively [1-3]. It has been described in patients after rapid weight loss and after corrective surgery of spinal deformities [4], either with instrumentation or with application of a body cast [2, 5, 6], usually during the first postoperative week [7-10]. It has also been reported following a spica cast [11].

We present here a case of SMAS, where the symptoms ensued 4 years after surgery.

\section{Case report}

A 12-year-old autistic, nonverbal, and developmentally delayed female, 2 years post-menarchal and underweight

\footnotetext{
*Corresponding author: dormans@email.chop.edu
}

(height $155 \mathrm{~cm}$, weight $36.2 \mathrm{~kg}$, and BMI $14.97 \mathrm{~kg} / \mathrm{m}^{2}$ ), underwent instrumented posterior spinal fusion for progressive scoliosis (Figures 1 and 2).

Two years after the surgery, the patient showed increased agitation, anxiety, and autistic behavior. Whether these symptoms heralded or were possibly part of the clinical presentation of her later diagnosed SMAS cannot be confirmed. There was no vomiting or blood in stools, but it was difficult to determine whether she had abdominal pain. She had normal bowel movements and was "potty-trained". Five years after surgery she was evaluated by a GI specialist for consistent weight loss over a year (Figures 3 and 4). Workup ruled out metabolic disorders, cystic fibrosis, and poor caloric intake with sweat test, serum amino acids, and urine organic acids within normal. Upper GI barium study showed immediate failure of the contrast to cross to the left side of the spine, but crossing minutes later with the incomplete nature of the obstruction (Figure 5), and to-and-fro motility between the third and second portions of the duodenum, consistent with SMAS. The diagnosis being confirmed, the gastroenterologist started the patient on a nutrition diet, increasing caloric intake to $2000-3000 \mathrm{Cal} / \mathrm{day}$. 


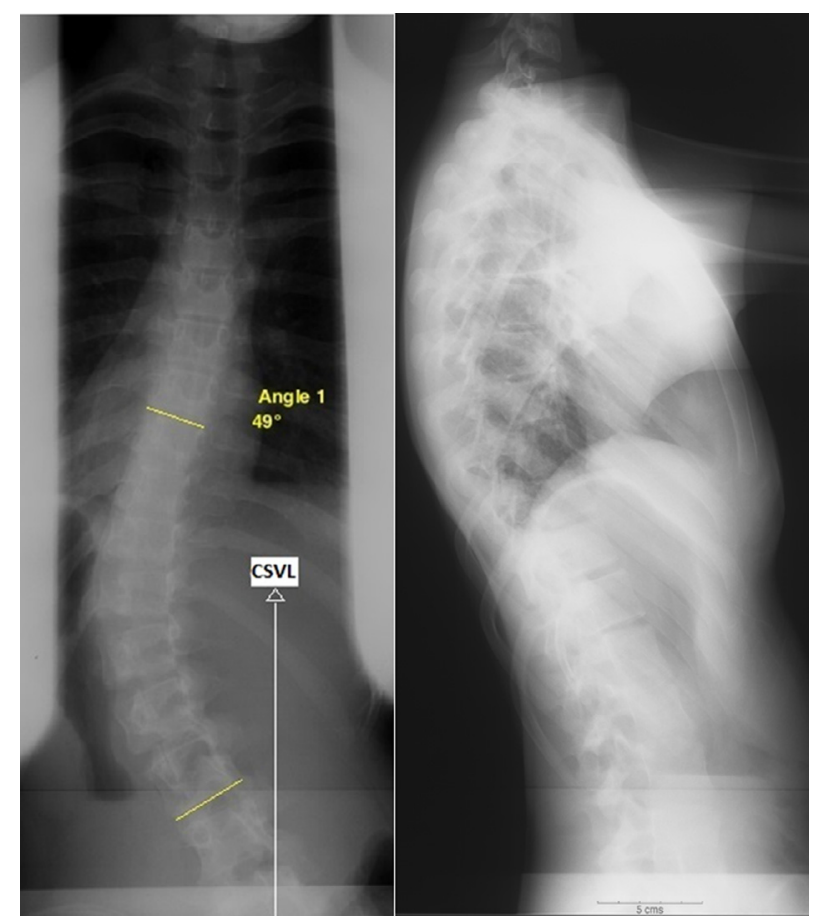

Figure 1. Preoperative spine radiographs showing scoliosis of $49^{\circ}$ and the center sacral vertical line (CSVL) falling medial to the apical lumbar vertebra, a C lumbar modifier [34].

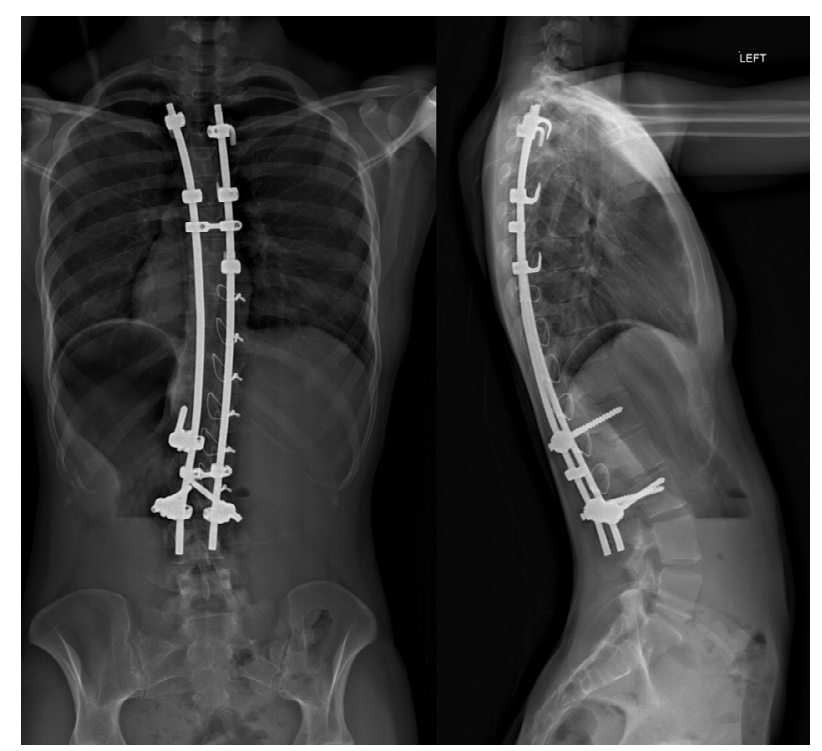

Figure 2. Latest follow-up radiographs 10 years after surgery.

Her symptoms improved and she gained some weight, but has always maintained a BMI below $16 \mathrm{~kg} / \mathrm{m}^{2}$.

Ten years after surgery, with a small appetite, the patient seems to have enough energy and menstruates regularly. She works Fridays and goes outdoors with an aide. Her latest radiographs (Figure 2) show good trunk balance and solid spinal fusion with intact instrumentation.

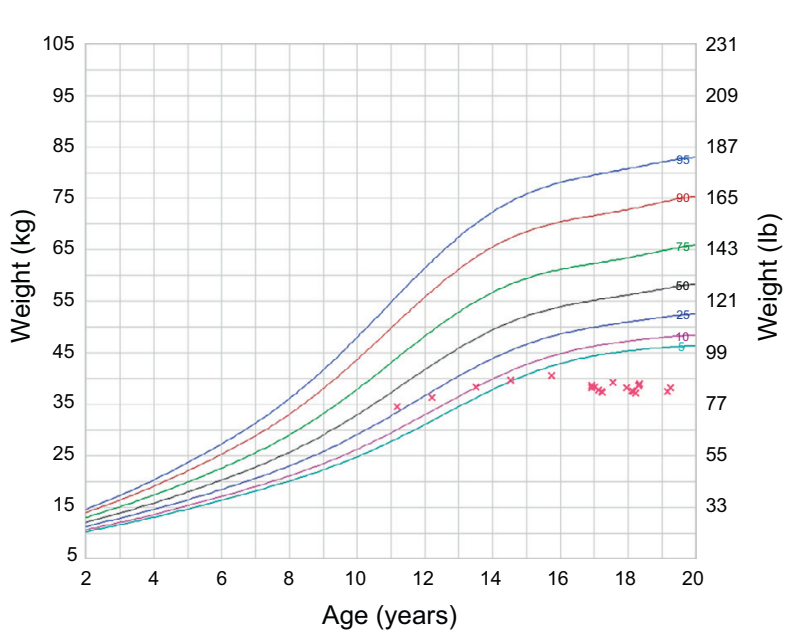

Figure 3. Weight for age chart of the patient showing consistent loss of weight captured around the age of 17,5 years after surgery.

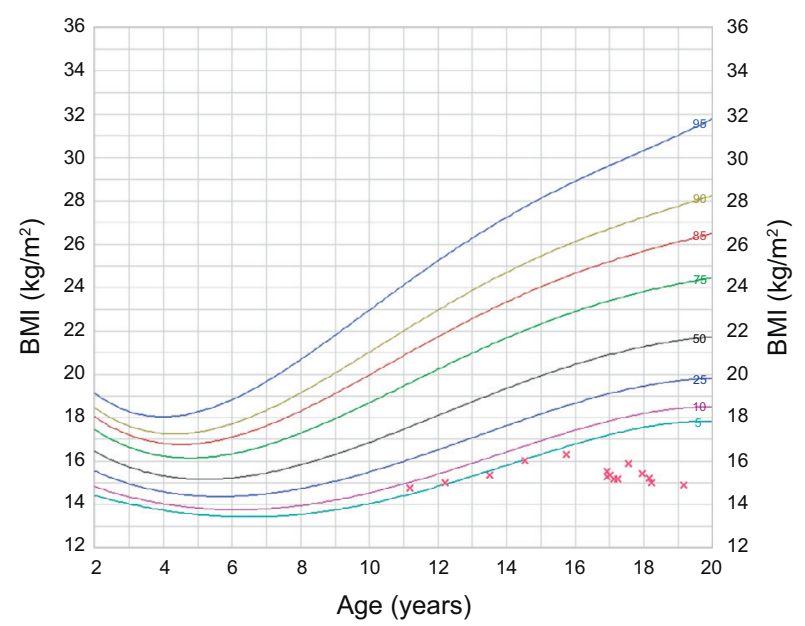

Figure 4. BMI for age chart of the patient showing generally low values with a drop captured around the age of 17,5 years after surgery.

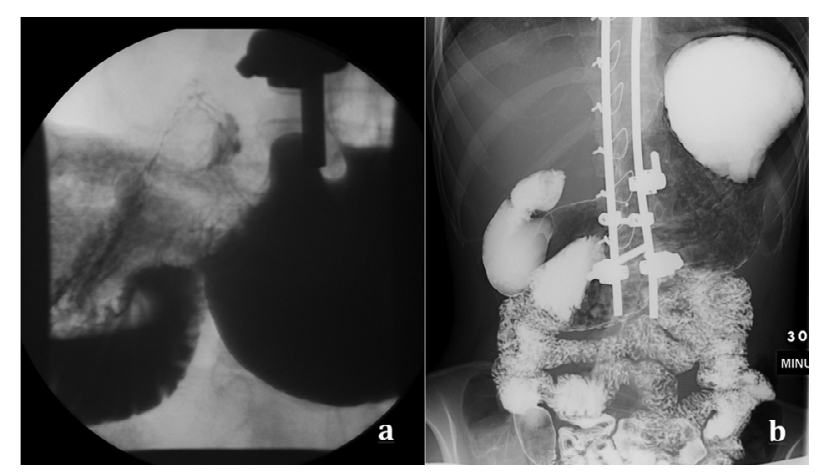

Figure 5. Barium Upper GI Study showing dilation of the stomach, 1st and 2nd parts of the duodenum. (a) Contrast not crossing to the left of the midline immediately after ingestion, (b) partial obstruction allowing some contrast into the jejunum later on. 


\section{Discussion}

SMAS has been reported after scoliosis surgery with a generally low incidence $(1-4.7 \%)[2,8,10,12]$, possibly due to relative lengthening of the spine increasing tension and narrowing the aortomesenteric angle [4, 13]. Also known as Cast Syndrome, SMAS is an uncommon, but a known, complication after the application of body casts [2, 5, 6, 14]. SMAS has also been reported to happen unrelated to spine surgery or casts, secondary to weight loss due to TB Cachexia [15], anorexia nervosa [16, 17], and other morbidities [18-20]. SMAS becomes self-perpetuating with a cycle of vomiting leading to further weight loss [4], and may co-occur with anterior nutcracker syndrome, with compression of the left renal vein $[3,21]$.

Symptoms of SMAS typically develop within a few days following scoliosis surgery $[7,9,10,22,23]$. Two cases were reported with somewhat delayed onset; a 14-year-old with SMAS progressed rapidly to death 40 days after scoliosis correction with Harrington instrumentation and application of a body cast [24]. Another presented 45 days after anterior spinal arthrodesis with postoperative bracing, but was treated conservatively with a favorable outcome [9]. In this case report, our patient presented as late as 5 years after her scoliosis surgery, which, to our knowledge, has not been previously reported.

In this report, we present a case of SMA syndrome with a subtle and unclear clinical presentation. Departing from the typical symptoms of SMA syndrome, known to be vomiting (92.9\%), abdominal pain $(57.1 \%)$, distension $(42.9 \%)$, bilious vomiting (35.7\%) [25], and hypoactive bowel sounds (28.6\%) [9, 25], our patient collectively suffered agitation, anxiety, increased autistic behavior, possible abdominal pain, and weight loss.

A staged procedure, the lumbar modifier of $\mathrm{B}$ or $\mathrm{C}$ as opposed to A, body mass index (BMI) $<25$ th percentile, and increased stiffness of the thoracic curve are the most predictive of the development of SMAS after spinal deformity correction [2].

Barium Upper Gastrointestinal (GI) series was the key to diagnosis in our patient after exclusion of other differential diagnoses. The traditional diagnostic method for SMAS is the barium upper GI series, with four diagnostic criteria [26-28]. Magnetic resonance angiography and CT are used to evaluate the aortomesenteric angle [29]. Endoscopic ultrasound could determine both the pulsatile character of the duodenal compression and the reduced aortomesenteric distance at the site of stenosis [29].

The lack of high indices of clinical suspicion can cause diagnostic delays $[4,25,30]$ and complications e.g. esophageal stricture [31]. The task is more demanding in the setting of a nonverbal patient with autism and mental retardation as in the patient we report here, especially in the absence of a known triggering factor. Our patient had higher odds of developing SMAS with a preoperative $\mathrm{BMI}<25$ th percentile and a $\mathrm{C}$ lumbar modifier of her curve (Figure 1). The diagnosis of SMAS was suspected by her gastroenterologist based on a high index of suspicion, given her preoperative low BMI, her curve characteristics, and her presentation with consistent weight loss, and was confirmed by the Upper GI barium study. It is not clear in this patient, whether SMAS was triggered by an initial loss of weight, or has, on the other hand, been multifactorial, facilitated by her earlier scoliosis surgery. The initial treatment for SMAS should aim at correction of electrolyte imbalances, stomach decompression, and nutritional support (nasojejunal feeds or total parenteral nutrition) [32]. Medical treatment is attempted for at least 6 weeks before surgery is considered [28]. Patients with chronic disease and malnutrition despite conservative treatment may require surgical intervention $[3,33]$. In our patient, conservative treatment alone was successful in increasing body weight, and improving her symptoms.

\section{Conclusion}

The importance of maintaining a high index of clinical suspicion for SMAS cannot be overemphasized, specifically in patients who are at higher risk and who are unable to communicate. Although the onset of SMAS reported after scoliosis surgery did not exceed a few weeks, our patient had onset of GI-related symptoms, in the form of weight loss, and possible abdominal pain as late as 4 years after surgery. SMAS should take its place on the list of differential diagnosis even in the presence of non-GI-related symptoms, especially in nonverbal patients, to avoid diagnostic delay and prevent complications.

\section{Conflict of interest}

NA, MK and JPD declare no conflict of interest in relation with this paper.

Acknowledgements. A written patient's consent has been obtained prior to submission of this report. The IRB at our institution does not consider illustrative reports of a single patient (case report) to meet the definition of research. There were no sources of financial or material support for this report.

\section{References}

1. Agrawal S, Nagraj S, Chaube R (2010) Renal tubular acidosis and superior mesenteric artery syndrome. BMJ Case Rep July, 2010.

2. Braun SV, Hedden DM, Howard AW (2006) Superior mesenteric artery syndrome following spinal deformity correction. J Bone Joint Surg Am 88(10), 2252-2257.

3. Welsch T, Buchler MW, Kienle P (2007) Recalling superior mesenteric artery syndrome. Dig Surg 24(3), 149-156.

4. Merrett ND, Wilson RB, Cosman P, Biankin AV (2009) Superior mesenteric artery syndrome: diagnosis and treatment strategies. J Gastrointest Surg 13(2), 287-292.

5. Berk RN, Coulson DB (1970) The body cast syndrome. Radiology 94(2), 303-305.

6. Sprague J (1998) Cast syndrome: the superior mesenteric artery syndrome. Orthop Nurs 17(4), 12-15, quiz 16-17.

7. Altiok H, Lubicky JP, DeWald CJ, Herman JE (2005) The superior mesenteric artery syndrome in patients with spinal deformity. Spine (Phila Pa 1976) 30(19), 2164-2170.

8. Hod-Feins R, Copeliovitch L, Abu-Kishk I, Eshel G, Lotan G, Shalmon E, Anekstein Y, Mirovsky Y, Masharawi Y (2007) Superior mesenteric artery syndrome after scoliosis repair surgery: a case study and reassessment of the syndrome's pathogenesis. J Pediatr Orthop B 16(5), 345-349. 
9. Tsirikos AI, Anakwe RE, Baker AD (2008) Late presentation of superior mesenteric artery syndrome following scoliosis surgery: a case report. J Med Case Rep 2, 9.

10. Zhu ZZ, Qiu Y (2005) Superior mesenteric artery syndrome following scoliosis surgery: its risk indicators and treatment strategy. World J Gastroenterol 11(21), 3307-3310.

11. Chen SH, Chen WS, Chuang JH (1992) Superior mesenteric artery syndrome as a complication in hip spica application for immobilization: report of a case. J Formos Med Assoc 91(7), 731-733.

12. Tsirikos AI, Jeans LA (2005) Superior mesenteric artery syndrome in children and adolescents with spine deformities undergoing corrective surgery. J Spinal Disord Tech 18(3), 263-271.

13. Sapkas G, O’Brien JP (1981) Vascular compression of the duodenum (cast syndrome) associated with the treatment of spinal deformities. A report of six cases. Arch Orthop Trauma Surg 98(1), 7-11.

14. Dorph MH (1950) The cast syndrome; review of the literature and report of a case. N Engl J Med 243(12), 440-442.

15. Limaye CS, Karande SP, Aher SP, Pati KA (2011) Superior mesenteric artery syndrome secondary to tuberculosis induced cachexia. J Assoc Physicians India 59, 670-671.

16. Adson DE, Mitchell JE, Trenkner SW (1997) The superior mesenteric artery syndrome and acute gastric dilatation in eating disorders: a report of two cases and a review of the literature. Int J Eat Disord 21(2), 103-114.

17. Lee CW, Park MI, Park SJ, Moon W, Kim HH, Kim BJ, Shim IK, Park SS (2011) A case of superior mesenteric artery syndrome caused by anorexia nervosa. Korean J Gastroenterol 58(5), 280-283.

18. Barnes JB, Lee M (1996) Superior mesenteric artery syndrome in an intravenous drug abuser after rapid weight loss. South Med J 89(3), 331-334.

19. Bedaiwi M, Alkubeyyer MA, Al Arfaj AS (2014) Superior mesenteric artery syndrome and intra-abdominal compartment syndrome in systemic lupus erythematosus. Lupus 23(2), 194-196.

20. Reckler JM, Bruck HM, Munster AM, Curreri PW, Pruitt BA Jr (1972) Superior mesenteric artery syndrome as a consequence of burn injury. J Trauma 12(11), 979-985.

21. Barsoum MK, Shepherd RF, Welch TJ (2008) Patient with both wilkie syndrome and nutcracker syndrome. Vasc Med 13(3), 247-250.

22. Vitale MG, Higgs GB, Liebling MS, Roth N, Roye DP Jr (1999) Superior mesenteric artery syndrome after segmental instrumentation: a biomechanical analysis. Am J Orthop (Belle Mead NJ) 28(8), 461-467.

23. Zadegan F, Lenoir T, Drain O, Dauzac C, Leroux R, Morel E, Guigui P (2007) Superior mesenteric artery syndrome following correction of spinal deformity: case report and review of the literature. Rev Chir Orthop Reparatrice Appar Mot 93(2), 181-185.

24. Kennedy RH, Cooper MJ (1983) An unusually severe case of the cast syndrome. Postgrad Med J 59(694), 539-540.

25. Lam DJ, Lee JZ, Chua JH, Lee YT, Lim KB (2014) Superior mesenteric artery syndrome following surgery for adolescent idiopathic scoliosis: a case series, review of the literature, and an algorithm for management. J Pediatr Orthop B 23(4), 312-318.

26. Eaton SB, Ferrucci JT (1973) Radiology of the pancreas and duodenum, Philadelphia, Saunders.

27. Hines JR, Gore RM, Ballantyne GH (1984) Superior mesenteric artery syndrome. diagnostic criteria and therapeutic approaches. Am J Surg 148(5), 630-632.

28. Shin MS, Kim JY (2013) Optimal duration of medical treatment in superior mesenteric artery syndrome in children. J Korean Med Sci 28(8), 1220-1225.

29. Lippl F, Hannig C, Weiss W, Allescher HD, Classen M, Kurjak M (2002) Superior mesenteric artery syndrome: diagnosis and treatment from the gastroenterologist's view. J Gastroenterol 37(8), 640-643.

30. Shiu JR, Chao HC, Luo CC, Lai MW, Kong MS, Chen SY, Chen CC, Wang CJ (2010) Clinical and nutritional outcomes in children with idiopathic superior mesenteric artery syndrome. J Pediatr Gastroenterol Nutr 51(2), 177-182.

31. Sinagra E, Montalbano LM, Linea C, Giunta M, Tese L, La Seta F, Malizia G, Orlando A, Marasa M, D’Amico G (2012) Delayedonset superior mesenteric artery syndrome presenting as oesophageal peptic stricture. Case Rep Gastroenterol 6(1), 94-102.

32. Li J, Chousleb E, Hidalgo J, Patel S, Szomstein S, Rosenthal RJ (2011) Laparoscopic Roux-en-Y duodenojejunal bypass for superior mesenteric artery syndrome: case reports and review of the literature. Surg Laparosc Endosc Percutan Tech 21(6), e344-347.

33. Kim IY, Cho NC, Kim DS, Rhoe BS (2003) Laparoscopic duodenojejunostomy for management of superior mesenteric artery syndrome: two cases report and a review of the literature. Yonsei Med J 44(3), 526-529.

34. Lenke LG, Betz RR, Harms J, Bridwell KH, Clements DH, Lowe TG, Blanke K (2001) Adolescent idiopathic scoliosis: a new classification to determine extent of spinal arthrodesis. J Bone Joint Surg Am 83-A(8), 1169-1181.

Cite this article as: Abol Oyoun N, Kadhim M \& Dormans JP (2015) Late-onset superior mesenteric artery syndrome four years following scoliosis surgery - a case report. SICOT J, 1, 12 